\title{
Sleep Patterns During Hospitalization Following Hematopoietic Stem Cell Transplantation
}

\author{
Eileen Danaher Hacker, PhD, RN, AOCN ${ }^{\circledR}$, FAAN [associate professor], \\ College of Nursing at the University of Illinois at Chicago \\ Mary Catherine Kapella, PhD, RN [assistant professor], Chang Park, PhD [research \\ assistant professor], \\ College of Nursing at the University of Illinois at Chicago
}

Carol E. Ferrans, PhD, RN, FAAN [professor and associate dean for research], and College of Nursing at the University of Illinois at Chicago

Janet L. Larson, PhD, RN, FAAN [professor]

School of Nursing at the University of Michigan in Ann Arbor

\section{Abstract}

Purpose/Objectives-To characterize patient-reported and objective sleep assessments and provide a preliminary examination of the relationships among sleep, quality of life, and demographic or treatment factors.

Design-A secondary data analysis using a descriptive-correlational design.

Setting-University of Illinois Hospital and Health Sciences System.

Sample-40 patients undergoing a hematopoietic stem cell transplantation (HCT) hospitalized for the conditioning regimen, stem cell infusion, and immediate recovery period.

Methods-Each patient wore a wrist actigraph continuously from the fourth day following HCT to the eighth day to objectively assess sleep patterns (total sleep time, sleep onset latency, sleep efficiency, wake after sleep onset, and number of awakenings). At the end of the five-day period, patients completed measures of sleep disturbance and quality of life.

Main Research Variables-Objective sleep (total sleep time, sleep onset latency, sleep efficiency, wake after sleep onset, and number of awakenings), subjective sleep (sleep disturbance), and quality of life.

Findings-The mean total nighttime sleep (objectively obtained) was 232 minutes ( $\mathrm{SD}=71$ minutes), with 14 patients (35\%) sleeping less than three consecutive hours during one or more study days. Age was negatively correlated with patient-reported sleep disturbance. Patientreported sleep disturbance was significantly associated with length of hospital stay. No correlations were found between patient-reported and objective sleep assessments.

For permission to post online, reprint, adapt, or reuse, please pubpermissions@ons.org Hacker can be reached at ehacker@uic.edu, with copy to editor at ONFEditor@ons.org. 
Conclusions-This study objectively documents inadequate and irregular sleep in hospitalized patients undergoing HCT. Sole reliance on patient-reported sleep assessments may not represent the full extent of the problem.

Implications for Nursing-Attempts to streamline care during the night by not waking patients for routine care unless indicated by the patient's condition (as advocated by the American Academy of Nursing) and providing supportive care for symptoms (such as diarrhea) during the night may reduce the number of awakenings and possibly improve overall sleep quality.

\section{Keywords}

hematopoietic stem cell transplantation; sleep; sleep disturbances; hospitalization

Sleep is an essential, restorative, biologic process crucial for maintaining and optimizing health. In patients with cancer, sleep disturbance is one of the most frequently reported side effects (Howell et al., 2014). Following hematopoietic stem cell transplantation (HCT), the prevalence and severity of sleep disturbances is likely amplified, given the intensive nature of the chemotherapy, subsequent side effects, and potentially long hospital stays. As many as $77 \%$ of patients report problems with sleep during hospitalization following HCT (Rischer, Scherwath, Zander, Koch, \& Schulz-Kindermann, 2009). More than 30\% report sleep disturbances to be severely distressing on the day of transplantation (Bevans, Mitchell, $\&$ Marden, 2008). From a survivorship perspective, this problem may continue for years after transplantation (Bush, Donaldson, Haberman, Dacanay, \& Sullivan, 2000; Watson et al., 2004). Although a common complaint, sleep disturbances during hospitalization may be under-recognized as a significant threat to the well-being of patients undergoing HCT.

Sleep disturbances frequently worsen during hospitalization when the need for sleep to recover from illness is greatest (McKinley, Fien, Elliott, \& Elliott, 2013). Multiple factors potentially contribute to sleep disturbances during hospitalization following HCT, including (a) the simultaneous occurrence of multiple side effects, such as fatigue and diarrhea, from the pretransplantation conditioning regimen (Cohen et al., 2012; Hacker \& Ferrans, 2003); (b) required patient care provided during nighttime hours, such as vital sign assessment and/or medication administration (Boonstra et al., 2011; Hacker, Patel, \& Stainthorpe, 2013); and (c) hospital environment factors, such as noise and lights (Bernhofer, Higgins, Daly, Burant, \& Hornick, 2014).

Inadequate sleep has serious consequences (Hublin, Partinen, Koskenvuo, \& Kaprio, 2007; Verkasalo et al., 2005). In critically ill patients, sleep disturbances have been linked to slowed recovery from illness, immune dysfunction, changes in mental status, and diminished quality of life (QOL) (Friese, 2008; Kamdar, Needham, \& Collop, 2012). Sleeping less than 300 minutes per night is associated with a four-times greater increase in mortality risk compared to those sleeping more than 300 minutes (Kripke, Langer, Elliott, Klauber, \& Rex, 2011; Vgontzas et al., 2010). These risks may extend to patients undergoing HCT, but the literature is lacking regarding sleep duration in this patient population. Rischer et al. (2009) reported a mean total sleep time of 337 minutes in hospitalized patients undergoing HCT $(n=44)$, with $36 \%$ reporting 300 minutes or less per night. The data, however, were patient-reported. Discordance between patient-reported and 
objective measures of sleep have been found in other populations, with objective measures of total sleep time being significantly shorter than patient-reported measures (Van Den Berg et al., 2008). For this reason, a significant need exists to objectively assess sleep in hospitalized patients undergoing HCT.

Multiple methods, such as polysomnography, sleep diaries, and wrist actigraphy, have been used to assess sleep in clinical settings. Wrist actigraphy is particularly attractive for objective assessment of sleep in hospitalized patients given the non-intrusive nature of the assessment and the ability to continuously collect data during many days. In addition, growing research supports the use of wrist actigraphy to measure sleep in clinical settings (Morgenthaler et al., 2007). To the authors' knowledge, no studies have used objective sleep assessment methods, such as wrist actigraphy, in hospitalized patients undergoing HCT while in the acute recovery period. Information related to sleep patterns of patients undergoing $\mathrm{HCT}$ and factors contributing to sleep disturbances is needed to identify potential areas for intervention and mitigate the impact of inadequate sleep during hospitalization. The purpose of this study was to describe patient-reported and objective sleep during hospitalization immediately following HCT and conduct a preliminary examination of the relationships among sleep, QOL, demographic factors, and length of hospitalization.

\section{Methods}

The current study used a descriptive-correlational design to examine patient-reported sleep, objective sleep, and QOL in hospitalized patients undergoing HCT. Patient-reported sleep was measured using the single sleep disturbance item from the European Organisation for Research and Treatment of Cancer Quality of Life Questionnaire-Core 30 (EORTC QLQC30) on the eighth day following HCT. Objective sleep (total sleep time, sleep onset latency, sleep efficiency, wake after sleep onset [WASO], and number of awakenings) was assessed using wrist actigraphy from the fourth day following HCT through the eighth. QOL was measured using the EORTC QLQ-C30, which includes global QOL, five functional scales, and multi- and single-item symptom scales on the eighth day following the HCT (Aaronson, Cull, Kaasa, \& Sprangers, 1996). This was a secondary data analysis of data from three previous studies (Hacker et al., 2006; Hacker, Larson, Kujath, et al., 2011; Hacker, Larson, \& Peace, 2011). One study was a two-site descriptive study examining fatigue and physical activity following HCT (Hacker et al., 2006). Only patients from the University of Illinois Hospital and Health Sciences System were included in the current study because of the inability to gain access to the outside facility's electronic medical record after the initial data collection procedures were completed. Institutional review board approval was obtained for the three studies from the University of Illinois at Chicago. The objective sleep data had not been previously analyzed, so the data were pooled because the instrumentation and data collection procedures were identical in each of the studies.

\section{Sample and Setting}

Forty patients hospitalized for the conditioning regimen, stem cell infusion, and immediate recovery period were included in this sample. All were inpatients on a dedicated blood and 
marrow transplantation unit at an academic medical center. Initial eligibility criteria included (a) patients scheduled to receive a hematopoietic stem cell transplantation for a malignancy, (b) the ability to speak English, (c) the ability to comprehend the purpose of the study, and (d) no history of a psychiatric illness. Objective sleep assessments were conducted for each of the 40 patients during four nights for a total of 160 nights.

\section{Instrumentation}

Patient-reported sleep disturbance-Patient-reported sleep disturbance was assessed using a single item from the EORTC QLQ-C30 (Aaronson et al., 1996). Patients were asked to respond on a four-point Likert-type scale to the question "Have you had trouble sleeping?" during the past week. Scores were converted to a 0-100 scale according to established guidelines, with higher scores indicating higher levels of sleep disturbances. The mean published reference value for sleep in hospitalized patients undergoing HCT is 50 (SD = 38) (Grulke, Albani, \& Bailer, 2012).

Objective sleep variables-Sleep was objectively measured using a wrist-worn accelerometer, the Actiwatch-Score ${ }^{\mathrm{TM}}$. The omni-directional accelerometer uses a piezoelectric sensor to monitor the occurrence and degree of motion. The motion sensor integrates degree and speed of motion, and this information is stored on board in the Actiwatch-Score memory as activity counts. The data were stored in one-minute epochs. The activity counts were scored as sleep or wake epochs using the Actiwatch software. The software automatically assigned rest, sleep, and active intervals based on activity counts and used an automated analysis to determine sleep start by searching for the first 10 minutes during which no more than one epoch was scored as "wake." The default software settings were used for the analysis. The sleep parameters produced include total sleep time, sleep latency (minutes until sleep onset), sleep efficiency, frequency and duration of WASO, and number of awakenings. Sleep variables were scored for each 24-hour period, and a mean was computed. Wrist actigraphy has been successfully used to assess sleep and sleep disturbances across a wide range of populations, including patients with cancer (Berger, 1998; Hacker et al., 2006; Miaskowski \& Lee, 1999; Sarna \& Conde, 2001). Intra- and interinstrument reliability was established using a shaker table under six different conditions of various intensity to produce a range of accelerometry counts (Esliger \& Tremblay, 2006). Wrist actigraphy is highly correlated with polysomnography, the gold standard for assessing sleep (Ancoli-Israel et al., 2003). Compared to polysomnography, wrist actigraphy has been found to be highly accurate (86\%) and sensitive (96\%) for detecting sleep (Marino et al., 2013).

Quality of life-The EORTC QLQ-C30 was used to measure QOL. This well-established instrument consists of a global QOL/health status scale, five multi-item functional scales (physical, cognitive, emotional, role, and social functioning), three multi-item symptom scales (pain, fatigue, and nausea and vomiting), and a number of single-item questions (appetite loss, constipation, diarrhea, dyspnea, sleep disturbance, and financial impact) (Aaronson et al., 1996). Items on the multi-item subscales are averaged and then converted to a scale with a range of $0-100$. Higher scores on the global QOL/health status and five functional scales represent better QOL and a higher level of functioning. Higher scores on 
the symptom scales and the single-item questions indicate a higher degree of symptomatology and, therefore, a poorer QOL. High internal consistency has been reported for all of the multi-item subscales (range $=0.8-0.94$ ) (Aaronson et al., 1993; Osoba et al., 1994). Published reference values for patients undergoing HCT are available for all subscales and single items (Grulke et al., 2012).

\section{Data Collection Procedures}

Wrist actigraphy data collection occurred during a five-day/four-night period (96 hours continuously) while patients were hospitalized for HCT, beginning on the fourth day and ending on the eighth day post-transplantation. This time period was selected to coincide with the period of profound neutropenia and the impact of acute side effects to provide data during this critical phase of the transplantation trajectory. Wrist actigraphs were placed on the patient's nondominant hand. Patients were instructed to carry on with normal activities and to wear the device continuously. At the end of the five-day period, the wrist actigraphs were removed and patients completed the questionnaires via interview.

\section{Data Analysis}

All data analyses were performed using SPSS ${ }^{\circledR}$, version 21. Descriptive statistics were calculated for all variables. Using the Actiware software, the objective sleep data were analyzed in two ways: (a) nighttime sleep only (sleep lasting at least three hours per day) and (b) all sleep within a 24-hour period (nighttime sleep and daytime naps). Because hospitalized patients frequently nap during the day, it was important to address sleep from both perspectives. One-sample $t$ tests were used to examine differences among sleep parameters (total sleep time and sleep efficiency) in patients undergoing HCT compared to the clinical recommendations of the American Academy of Sleep Medicine (Schutte-Rodin, Broch, Buysse, Dorsey, \& Sateia, 2008). Independent t tests were used to examine differences in sleep variables based on gender and type of transplantation (autologous versus allogeneic). Correlations were computed to conduct a preliminary exploration of the relationships among sleep, QOL, demographic factors, and length of hospitalization.

\section{Results}

\section{Sample Characteristics}

Table 1 details the demographic and clinical characteristics of the sample. The mean age was 51.8 years $(\mathrm{SD}=14)$.

\section{Patient-Reported Sleep and Quality of Life}

Patient-reported variables (sleep and QOL) are reported in Table 2. Results indicate a high prevalence of patient-reported sleep disturbances during hospitalization following HCT. Thirty-two patients (82\%) reported some sleep disturbance, with 13 (33\%) reporting "very much" trouble sleeping in the past week, 6 (16\%) reporting "quite a bit," and 13 (33\%) reporting "a little." Patient-reported sleep disturbance was not correlated with any of the objective sleep assessments. Fatigue was the highest scored symptom $\left(\mathrm{X}^{-}=74.07, \mathrm{SD}=\right.$ 23.41), with only one participant reporting no problems and 10 reporting fatigue at the highest level of the range (i.e., 100). 


\section{Objective Sleep Assessments}

Descriptive statistics for objective sleep parameters are reported in Table 3. Figure 1 provides an example of sleep output (nighttime sleep only) obtained from the wrist actigraph. The expectation was that each patient would have four major sleep bouts lasting at least three hours during the 96-hour study period, corresponding to one major sleep bout per day (nighttime sleep). The results indicate that 26 patients (65\%) slept at least three consecutive hours during each of the four 24-hour study days, but the sleep times varied considerably. Conversely, 14 patients (35\%) did not sleep more than three consecutive hours during one or more study days. One patient did not sleep longer than three hours on any of the study days.

\section{Total Sleep Time and Efficiency Compared to Population Recommendations}

Results indicate that patients undergoing HCT had significantly less total sleep time and sleep efficiency compared to clinical recommendations of at least 6.5 hours (390 minutes) total sleep time and $85 \%$ sleep efficiency. The average total nighttime sleep time per 24hour period was 232 minutes ( $\mathrm{SD}=71$ minutes; $\mathrm{p} \leq 0.001)$ and 341 minutes $(\mathrm{SD}=141$ minutes) when nighttime sleep plus daytime naps were evaluated ( $\mathrm{p} \leq 0.05$ ). Likewise, sleep efficiency was significantly lower than the population recommendation of $85 \%$. Sleep efficiency was $42 \%$ for nighttime sleep ( $\mathrm{p} \leq 0.001$ ) and 55\% when nighttime sleep plus daytime naps during a 24-hour period were considered ( $\mathrm{p} \leq 0.001$ ).

\section{Gender and Type of Transplantation}

No significant differences were noted between men and women for most of the objective sleep parameters. The number of awakenings was the only significant difference $(\mathrm{p}<0.05)$, with men experiencing more awakenings $\left(\mathrm{X}^{-}=35, \mathrm{SD}=13\right)$ compared to women $\left(\mathrm{X}^{-}=25\right.$, $\mathrm{SD}=10)$. Patient-reported sleep disturbances approached significance $(\mathrm{p}=0.054)$ for differences between gender, with men reporting more sleep disturbances than women. Likewise, when autologous compared to allogeneic recipients were compared, only number of awakenings ( $\mathrm{p}<0.05$ ) was significantly different, with patients undergoing autologous HCT waking more often.

Age

Age was negatively correlated with patient-reported sleep disturbance $(r=-0.38, p<0.05)$. Younger patients reported more severe sleep disturbances. Age also was associated with multiple objective sleep parameters. When only nighttime sleep was evaluated, age was positively correlated with WASO $(r=0.36, \mathrm{p}<0.05)$. When nighttime sleep and daytime naps were evaluated, sleep latency was positively correlated $(r=0.39, p<0.05)$.

\section{Time From Transplantation to Discharge}

Length of hospitalization is considered to be an important indicator of patient acuity during hospitalization. The number of days from time from transplantation to hospital discharge was calculated for each patient. Days admitted to the hospital for the conditioning regimen were excluded because of variability in conditioning regimens. Time from transplantation to 
hospital discharge was positively correlated with patient-reported sleep disturbance $(\mathrm{r}=$ $0.48, \mathrm{p}<0.01$ ), but not with any of the objective sleep parameters.

\section{Objective Sleep Assessment Correlations}

To begin to understand the impact of inadequate sleep, the sleep parameters (nighttime sleep and daytime naps) were evaluated for associations with patient-reported variables (all subscales and individual items of the EORTC QLQ-C30). Total sleep time negatively correlated with physical functioning $(\mathrm{r}=-0.37, \mathrm{p}<0.05)$ and cognitive functioning $(\mathrm{r}=$ $-0.38, \mathrm{p}<0.05)$, and positively correlated with pain $(\mathrm{r}=0.36, \mathrm{p}<0.05)$, dyspnea $(\mathrm{r}=0.37$, $p<0.05)$, and appetite loss $(r=0.42, p<0.01)$. Sleep efficiency was greater in those with increased nausea and vomiting $(r=0.42, p<0.01)$ and/or pain $(r=0.37, p<0.05)$. Physical functioning correlated negatively with WASO $(\mathrm{r}=-0.35, \mathrm{p}<0.05)$ and number of awakenings $(r=-0.36, p<0.05)$. Sleep latency was not correlated with any patient-reported variables.

\section{Discussion}

The findings suggest that a substantial number of patients undergoing HCT experience sleep disturbances during the acute phase of HCT treatment, including sleeping less than three consecutive hours in a 24-hour period. In addition, the total sleep time and sleep efficiency were significantly lower than the general sleep recommendations advocated by the American Academy of Sleep Medicine (Schutte-Rodin et al., 2008). Total sleep time and sleep efficiency tend to be overestimated using wrist actigraphy compared to polysomnography (Lichstein et al., 2006); therefore, total sleep time and sleep efficiency may be even lower. Providing additional support for this, a study by McCall and McCall (2012) of people with insomnia reported wrist actigraphy overestimated mean total sleep time by 12.8 minutes $(\mathrm{SD}=7.5)$ and sleep efficiency by $2 \%(\mathrm{SD}=1.7 \%)$ when compared to polysomnography. Rischer et al. (2009) reported the average sleep duration during hospitalization as 337 minutes. Although this patient-reported sleep amount is consistent with the current authors' objectively obtained data for nighttime sleep plus daytime naps ( $\mathrm{X}^{-}$ $=341$ minutes), the authors' data for nighttime sleep alone were almost two hours shorter ( $\mathrm{X}^{-}$ $=232$ minutes). The current results, along with Rischer et al.'s (2009), suggest that hospitalized patients undergoing HCT are not getting adequate sleep in the hospital and, in the case of nighttime sleep only, the duration of sleep is substantially lower than the 300minute threshold associated with increased risk.

An average of 10 interactions per night were reported between patients and healthcare providers during the hours of 9 pm and 7 am, as previously reported in Hacker et al. (2013). The most frequent time for interactions occurred from 12 am to 1 am and 4 am to $5 \mathrm{am}$. Medication administration was the most frequently documented care provided at night, followed by vital sign measurement. Together, the findings from this study and the retrospective medical record review suggest that a great need exists to design care processes and develop interventions to address sleep disturbances in hospitalized patients undergoing HCT. 
The current study provides preliminary evidence for the role that age may play in developing sleep disturbances during hospitalization for HCT. In the current study, objective assessment by actigraphy demonstrated that older patients experienced more sleep disturbances. Paradoxically, younger patients reported more severe sleep disturbances. The reason for this discrepancy is unclear. Sleep disturbances in younger, hospitalized patients undergoing HCT may be a more novel experience, therefore eliciting a more pronounced self-reported response. Older HCT recipients may experience chronic problems with sleep prior to HCT. During hospitalization, older HCT recipients may judge the changes associated with sleep less severely; similar to the response shift observed with fatigue (Visser, Smets, Sprangers, \& de Haes, 2000). The literature suggests that this inverse relationship between self-reported sleep disturbances and age is not specific to HCT. A large study ( $\mathrm{N}=982$ ) involving patients with breast, gastrointestinal, genitourinary, gynecologic, lung, and non-melanoma skin cancers reported that patients were $26 \%$ less likely to report sleep disturbances with each passing decade (Davidson, MacLean, Brundage, \& Schulze, 2002). Together, these findings suggest that caution needs to be used when interpreting selfreported sleep disturbances in older patients because they may underestimate the prevalence and severity.

In the general public, serious consequences are associated with inadequate sleep, including impaired cognitive and physical functioning and their associated public health hazards, hypertension, obesity, type 2 diabetes, cardiovascular risks, and lower life expectancy (Hublin et al., 2007; Verkasalo et al., 2005), but these have not been studied in patients undergoing HCT. Because older patients are undergoing HCT at increased rates (Pasquini \& Wang, 2012), understanding the changes in sleep patterns and disturbances over time is important. Collecting sleep data using wrist actigraphy is particularly attractive for older recipients of HCT, given the non-intrusive nature of the measurement. In the current study, excellent compliance rates were observed, with all patients wearing the device continuously during the data collection period. Alhough this study is limited by the small sample size, more than 160 nights of sleep data were collected, providing further support for the usefulness of this type of objective assessment.

Framing sleep disturbances using the Behavioral Model of Insomnia may be helpful for advancing the science of sleep disturbances in patients undergoing HCT (Spielman, Caruso, \& Glovinsky, 1987). This model proposes that insomnia occurs acutely from predisposing and precipitating factors and can progress to chronic insomnia because of counterproductive coping behaviors. Identification and removal of contributing factors is an important consideration for improving sleep in patients undergoing HCT. Healthcare providers in the hospital setting can make concerted efforts to streamline care processes to avoid interrupting sleep at night. Even so, care requirements, such as around-the-clock IV administration of antibiotics, are unavoidable and may still result in sleep disturbances. Receiving pain medications and antiemetics for nausea and vomiting may inadvertently improve sleep through daytime naps, as evidenced by the positive correlation between total sleep time and pain, as well as nausea and vomiting. The clinical implications of daytime napping are poorly understood in hospitalized patients undergoing HCT and require additional investigation. For example, daytime naps may help to alleviate sleep deficits as a result of nighttime care requirements. On the other hand, daytime naps and daytime sleepiness may 
be an important indicator of health problems. A study of 16,374 men and women found that those who normally nap during the day had a $32 \%$ increase in all-cause mortality (Leng et al., 2014), but this has not been examined following HCT.

One surprising finding was the association between patient-reported sleep disturbance and time from HCT to discharge. The fact that this simple measure is associated with length of hospital stay illustrates the importance of ascertaining patient reports of symptoms and functioning. The relationship between self-reported sleep disturbances and length of stay is most likely bidirectional, as length of stay may be a surrogate measure for high patient acuity and/or transplantation-related complications. Higher acuity HCT recipients with more complications may report worse sleep caused by discomfort and/or the need for more frequent care during hospitalization. Of note, other self-reported measures typically associated with worsening physical health, such as self-reported physical functioning, were not associated with time from HCT to discharge. Although a causal relationship between patient-reported sleep disturbance and length of hospital stay cannot be determined, future research should further evaluate this relationship, as well as the impact of sleep interventions in hospitalized patients undergoing HCT on length of hospital stay.

\section{Limitations}

Although the current study provides important objective documentation of sleep in hospitalized patients, limitations exist. First, this study only documents sleep during hospitalization in patients undergoing HCT immediately following the procedure. In the authors' previously reported companion study, only one patient had documented sleep problems prior to hospitalization (Hacker et al., 2013). Long-term follow-up of those with inadequate sleep during hospitalization would help determine if sleep problems only occurred during hospitalization and require a hospital-focused intervention, or if sleep problems are long-term and, therefore, require a more comprehensive and long-term approach.

\section{Implications for Nursing}

Nurses play a key role in addressing the sleep needs of hospitalized patients undergoing HCT. In the acute care setting, assessing the quantity and quality of sleep is vital to identifying those with sleep disturbances or who are at risk for developing problems. Promoting adequate sleep in the hospital environment is an important nursing outcome. Reflecting the growing recognition that hospitalized patients need sleep, the American Academy of Nursing recommends that nurses not wake patients for routine care unless dictated by the patient's specific condition or care requirements as noted in the Choosing Wisely campaign (www.aannet.org/sleep). HCT nurses in the acute care setting are uniquely qualified to design care processes to achieve this outcome. Streamlining care and/or improving supportive care for symptoms (such as diarrhea) during the night may reduce the number of awakenings and improve overall sleep quality. Noise and light reduction strategies have been shown to improve patient's sleep (Li, Wang, Vivienne Wu, Liang, \& Tung, 2011). Providing evening or bedtime care, such as personal hygiene and relaxation measures, may also promote sleep (Lareau, Benson, Watcharotone, \& Manguba, 2008). Cognitive behavioral interventions to address sleep-wake disturbances are recommended for 
practice by the Oncology Nursing Society, with exercise and mindfulness-based stress reduction noted as likely to be effective (www.ons.org/practice-resources/pep/sleep-wakedisturbances). Attempts to streamline care also illustrate the paradox of promoting sleep in hospitalized patients undergoing HCT. The most acutely ill patients require the most frequent monitoring and provision of care, and those patients are the ones who will most likely be disturbed by care during the night. HCT nurses are challenged to provide nighttime care that is high quality, promotes sleep, and is efficient in minimizing unnecessary nighttime interactions to avoid unnecessary nighttime awakenings.

Future research should focus on the benefits and costs associated with using subjective and/or objective methods to assess sleep in hospitalized patients undergoing HCT. Although patient-reported methods are less expensive, they may or may not correlate with objective assessments, such as actigraphy. Conversely, actigraphy is less intrusive and may provide more complete data, given the high compliance rate noted in the current study. Actigraphy, however, requires specialized equipment and software and may be cost-prohibitive for largescale studies. Because sleep disturbances are frequently clustered with other symptoms, interventions to address sleep disturbances, such as cognitive behavioral therapy and/or exercise during hospitalization, may also result in improvements in fatigue, pain, and cognitive functioning.

\section{Conclusion}

In summary, sleep may be overlooked as a necessary component of hospital care in patients undergoing HCT because of complicated care requirements and competing physical needs. The current study documented inadequate and irregular sleep in hospitalized patients undergoing HCT and found it worse than that reported in Rischer et al. (2009). A substantial number of HCT recipients are sleeping considerably less than the minimum requirements of 300 minutes per night. Self-reported sleep disturbances following the transplantation may be an indicator of additional health problems, given the association with length of hospital study. Finally, relying only on patient-reported sleep assessments of sleep may be inadequate, particularly in older adult patients undergoing HCT who are at increased risk for complications following transplantation.

\section{References}

Aaronson NK, Ahmedzai S, Bergman B, Bullinger M, Cull A, Duez NJ, de Haes JC. The European Organization for Research and Treatment of Cancer QLQ-C30: A quality-of-life instrument for use in international clinical trials in oncology. Journal of the National Cancer Institute. 1993; 85:365376. [PubMed: 8433390]

Aaronson, NK.; Cull, AN.; Kaasa, S.; Sprangers, MA. Quality of life and pharmacoeconomics. 2nd ed.. Philadelphia, PA: Lippincott-Raven; 1996.

Ancoli-Israel S, Cole R, Alessi C, Chambers M, Moorcroft W, Pollak CP. The role of actigraphy in the study of sleep and circadian rhythms. Sleep. 2003; 26:342-392. [PubMed: 12749557]

Berger AM. Patterns of fatigue and activity and rest during adjuvant breast cancer chemotherapy. Oncology Nursing Forum. 1998; 25:51-62. [PubMed: 9460773]

Bernhofer EI, Higgins PA, Daly BJ, Burant CJ, Hornick TR. Hospital lighting and its association with sleep, mood and pain in medical inpatients. Journal of Advanced Nursing. 2014; 70:1164-1173. [PubMed: 24164506] 
Bevans MF, Mitchell SA, Marden S. The symptom experience in the first 100 days following allogeneic hematopoietic stem cell transplantation (HSCT). Supportive Care in Cancer. 2008; 16:1243-1254. [PubMed: 18322708]

Boonstra L, Harden K, Jarvis S, Palmer S, Kavanaugh-Carveth P, Barnett J, Friese C. Sleep disturbance in hospitalized recipients of stem cell transplantation. Clinical Journal of Oncology Nursing. 2011; 15:271-276. [PubMed: 21624862]

Bush NE, Donaldson GW, Haberman MH, Dacanay R, Sullivan KM. Conditional and unconditional estimation of multidimensional quality of life after hematopoietic stem cell transplantation: A longitudinal follow-up of 415 patients. Biology of Blood and Marrow Transplantation. 2000; 6:576591. [PubMed: 11071263]

Cohen MZ, Rozmus CL, Mendoza TR, Padhye NS, Neumann J, Gning I, Cleeland CS. Symptoms and quality of life in diverse patients undergoing hematopoietic stem cell transplantation. Journal of Pain and Symptom Management. 2012; 44:168-180. [PubMed: 22699091]

Davidson JR, MacLean AW, Brundage MD, Schulze K. Sleep disturbance in cancer patients. Social Science and Medicine. 2002; 54:1309-1321. [PubMed: 12058848]

Esliger DW, Tremblay MS. Technical reliability assessment of three accelerometer models in a mechanical setup. Medicine and Science in Sports and Exercise. 2006; 38:2173-2181. [PubMed: 17146326]

Friese RS. Sleep and recovery from critical illness and injury: A review of theory, current practice, and future directions. Critical Care Medicine. 2008; 36:697-705. [PubMed: 18176314]

Grulke N, Albani C, Bailer H. Quality of life in patients before and after haematopoietic stem cell transplantation measured with the European Organization for Research and Treatment of Cancer (EORTC) Quality of Life Core Questionnaire QLQ-C30. Bone Marrow Transplant. 2012; 47:473482. [PubMed: 21602898]

Hacker ED, Ferrans C, Verlen E, Ravandi F, van Besien K, Gelms J, Dieterle N. Fatigue and physical activity in patients undergoing hematopoietic stem cell transplant. Oncology Nursing Forum. 2006; 33:614-624. [PubMed: 16676017]

Hacker ED, Ferrans CE. Quality of life immediately after peripheral blood stem cell transplantation. Cancer Nursing. 2003; 26:312-322. [PubMed: 12886122]

Hacker ED, Larson J, Kujath A, Peace D, Rondelli D, Gaston L. Strength training following hematopoietic stem cell transplantation. Cancer Nursing. 2011; 34:238-249. [PubMed: 21116175]

Hacker ED, Larson JL, Peace D. Exercise in patients receiving hematopoietic stem cell transplantation: Lessons learned and results from a feasibility study. Oncology Nursing Forum. 2011; 38:216-223. [PubMed: 21356659]

Hacker ED, Patel P, Stainthorpe M. Sleep interrupted: Nocturnal care disturbances following hematopoietic stem cell transplantation. Clinical Journal of Oncology Nursing. 2013; 17:517-523. [PubMed: 24080050]

Howell D, Oliver TK, Keller-Olaman S, Davidson JR, Garland S, Samuels C, Taylor C. Sleep disturbance in adults with cancer: A systematic review of evidence for best practices in assessment and management for clinical practice. Annals of Oncology. 2014; 25:791-800. [PubMed: 24287882]

Hublin C, Partinen M, Koskenvuo M, Kaprio J. Sleep and mortality: A population-based 22-year follow-up study. Sleep. 2007; 30:1245-1253. [PubMed: 17969458]

Kamdar BB, Needham DM, Collop NA. Sleep deprivation in critical illness: Its role in physical and psychological recovery. Journal of Intensive Care Medicine. 2012; 27:97-111. [PubMed: 21220271]

Kripke DF, Langer RD, Elliott JA, Klauber MR, Rex KM. Mortality related to actigraphic long and short sleep. Sleep Medicine. 2011; 12:28-33. [PubMed: 20870457]

Lareau R, Benson L, Watcharotone K, Manguba G. Examining the feasibility of implementing specific nursing interventions to promote sleep in hospitalized elderly patients. Geriatric Nursing. 2008; 29:197-206. [PubMed: 18555161]

Leng Y, Wainwright NW, Cappuccio FP, Surtees PG, Hayat S, Luben R, Khaw KT. Daytime napping and the risk of all-cause and cause-specific mortality: A 13-year follow-up of a British population. American Journal of Epidemiology. 2014; 179:1115-1124. [PubMed: 24685532] 
Li SY, Wang TJ, Vivienne Wu SF, Liang SY, Tung HH. Efficacy of controlling night-time noise and activities to improve patients' sleep quality in a surgical intensive care unit. Journal of Clinical Nursing. 2011; 20(3-4):396-407. [PubMed: 21219521]

Lichstein KL, Stone KC, Donaldson J, Nau SD, Soeffing JP, Murray D, Aguillard RN. Actigraphy validation with insomnia. Sleep. 2006; 29:232-239. [PubMed: 16494091]

Marino M, Li Y, Rueschman MN, Winkelman JW, Ellenbogen JM, Solet JM, Buxton OM. Measuring sleep: Accuracy, sensitivity, and specificity of wrist actigraphy compared to polysomnography. Sleep. 2013; 36:1747-1755. [PubMed: 24179309]

McCall C, McCall WV. Comparison of actigraphy with polysomnography and sleep logs in depressed insomniacs. Journal of Sleep Research. 2012; 21:122-127. [PubMed: 21447050]

McKinley S, Fien M, Elliott R, Elliott D. Sleep and psychological health during early recovery from critical illness: An observational study. Journal of Psychosomatic Research. 2013; 75:539-545. [PubMed: 24290043]

Miaskowski C, Lee KA. Pain, fatigue, and sleep disturbances in oncology outpatients receiving radiation therapy for bone metastasis: A pilot study. Journal of Pain and Symptom Management. 1999; 17:320-332. [PubMed: 10355211]

Morgenthaler T, Alessi C, Friedman L, Owens J, Kapur V, Boehlecke B. Practice parameters for the use of actigraphy in the assessment of sleep and sleep disorders: An update for 2007. Sleep. 2007; 30:519-529. [PubMed: 17520797]

Osoba D, Zee B, Pater J, Warr D, Kaizer L, Latreille J. Psychometric properties and responsiveness of the EORTC quality of life questionnaire (QLQ-C30) in patients with breast, ovarian and lung cancer. Quality of Life Research. 1994; 3:353-364. [PubMed: 7841968]

Pasquini MC, Wang Z. Current uses and outcomes of hematopoietic stem cell transplantation [CIBMTR summary slides]. 2012 Retrieved from: http://www.cibmtr.org/ReferenceCenter/ SlidesReports/SummarySlides/Documents/SummarySlides_2012-revised1092013.pptx.

Rischer J, Scherwath A, Zander AR, Koch U, Schulz-Kindermann F. Sleep disturbances and emotional distress in the acute course of hematopoietic stem cell transplantation. Bone Marrow Transplantation. 2009; 44:121-128. [PubMed: 19151796]

Sarna L, Conde F. Physical activity and fatigue during radiation therapy: A pilot study using actigraph monitors. Oncology Nursing Forum. 2001; 28:1043-1046. [PubMed: 11475878]

Schutte-Rodin S, Broch L, Buysse D, Dorsey C, Sateia M. Clinical guideline for the evaluation and management of chronic insomnia in adults. Journal of Clinical Sleep Medicine. 2008; 4:487-504. [PubMed: 18853708]

Spielman AJ, Caruso LS, Glovinsky PB. A behavioral perspective on insomnia treatment. Psychiatric Clinics of North America. 1987; 10:541-553. [PubMed: 3332317]

Van Den Berg JF, Van Rooij FJ, Vos H, Tulen JH, Hofman A, Miedema HM, Tiemeier H. Disagreement between subjective and actigraphic measures of sleep duration in a population-based study of elderly persons. Journal of Sleep Research. 2008; 17:295-302. [PubMed: 18321246]

Verkasalo PK, Lillberg K, Stevens RG, Hublin C, Partinen M, Koskenvuo M, Kaprio J. Sleep duration and breast cancer: A prospective cohort study. Cancer Research. 2005; 65:9595-9600. [PubMed: 16230426]

Vgontzas AN, Liao D, Pejovic S, Calhoun S, Karataraki M, Basta M, Bixler EO. Insomnia with short sleep duration and mortality: The Penn State cohort. Sleep. 2010; 33:1159-1164. [PubMed: 20857861]

Visser MR, Smets EM, Sprangers MA, de Haes HJ. How response shift may affect the measurement of change in fatigue. Journal of Pain and Symptom Management. 2000; 20:12-18. [PubMed: 10946164]

Watson M, Buck G, Wheatley K, Homewood JR, Goldstone AH, Rees JK, Burnett KA. Adverse impact of bone marrow transplantation on quality of life in acute myeloid leukaemia patients: Analysis of the UK Medical Research Council AML 10 Trial. European Journal of Cancer. 2004; 40:971-978. [PubMed: 15093571] 


\section{Knowledge Translation}

Patients undergoing hematopoietic stem cell transplantation (HCT) frequently experience inadequate and irregular sleep during hospitalization following HCT.

Nurses are uniquely positioned to design care delivery that promotes sleep during hospitalization.

Developing interventions to address sleep disturbances in the hospital setting following HCT is an area that is key for nursing and interdisciplinary research. 


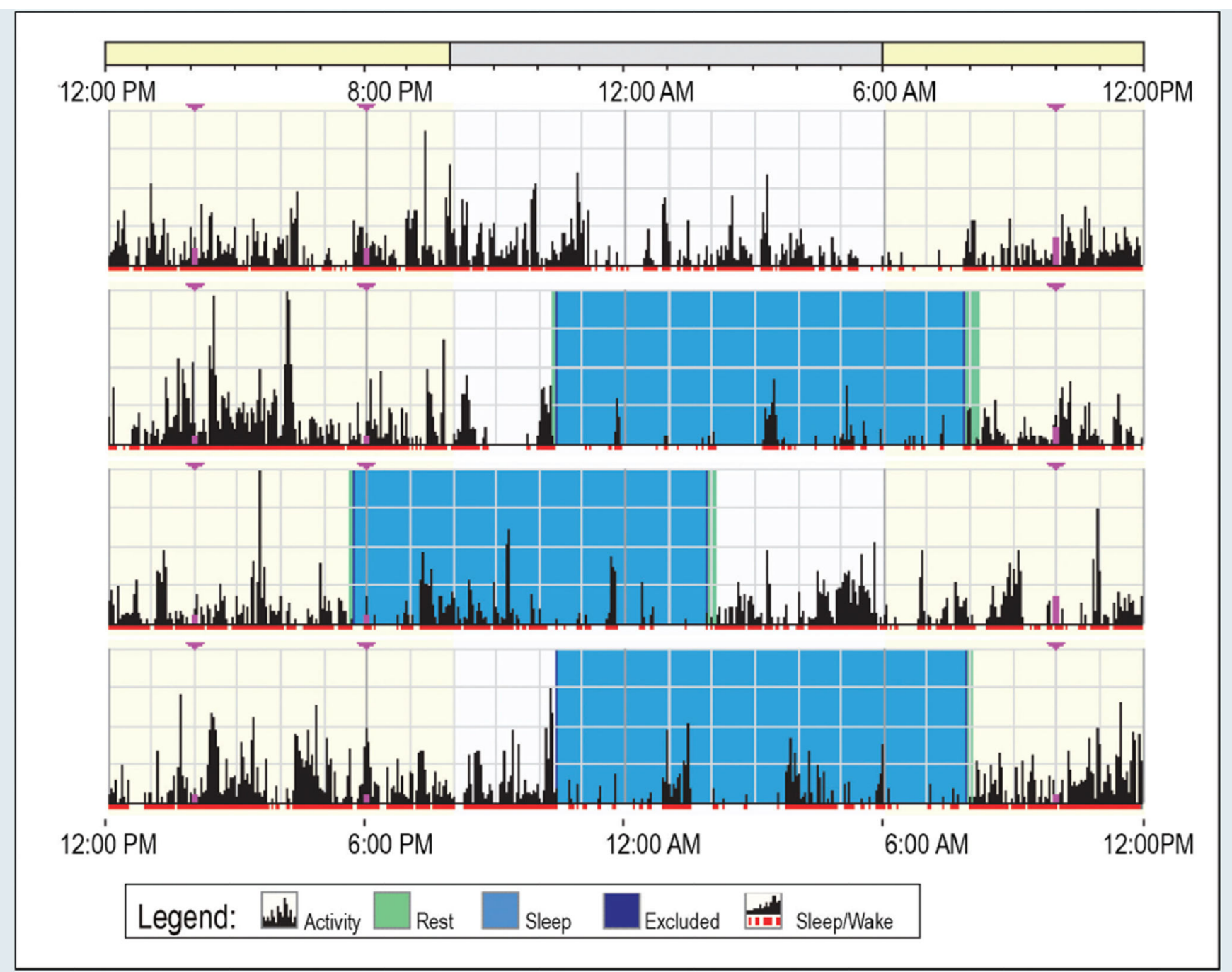

Figure 1. Example of Wrist Actigraphy Output

Note. Each line represents a 24-hour period. The time starts at $12 \mathrm{pm}$ and ends at $12 \mathrm{pm}, 24$ hours later. The black lines indicate physical activity, with height of the lines corresponding to the occurrence and degree of physical activity. Major sleep bouts lasting at least three hours are highlighted in blue. In this figure, although the mean time in bed is 9 hours, 21 minutes, the mean total nighttime sleep is only 193 minutes (a 34\% mean sleep efficiency) because of frequent awakenings. 


\section{Table 1}

Sample Characteristics $(\mathrm{N}=40)$

\begin{tabular}{|c|c|}
\hline Characteristic & $\mathbf{n}$ \\
\hline \multicolumn{2}{|l|}{ Gender } \\
\hline Male & 24 \\
\hline Female & 16 \\
\hline \multicolumn{2}{|l|}{ Race } \\
\hline Caucasian & 17 \\
\hline African American & 16 \\
\hline Latino, Hispanic, or Mexican American & 5 \\
\hline Asian, Pacific Islander, or other & 2 \\
\hline \multicolumn{2}{|l|}{ Marital status } \\
\hline Married & 23 \\
\hline Never married & 10 \\
\hline Divorced, separated, or widowed & 7 \\
\hline \multicolumn{2}{|l|}{ Education level } \\
\hline Eighth grade or less & 2 \\
\hline Some high school or less & 5 \\
\hline Graduated from high school & 13 \\
\hline Some college or more & 17 \\
\hline Graduated from college or graduate education & 3 \\
\hline \multicolumn{2}{|l|}{ Annual income (\$) } \\
\hline Less than 20,000 & 14 \\
\hline $21,000-40,000$ & 10 \\
\hline $41,000-60,000$ & 7 \\
\hline More than 61,000 & 8 \\
\hline Not provided & 1 \\
\hline \multicolumn{2}{|l|}{ Type of transplantation } \\
\hline Autologous & 25 \\
\hline Allogeneic & 15 \\
\hline \multicolumn{2}{|l|}{ Diagnosis } \\
\hline Multiple myeloma & 18 \\
\hline Non-Hodgkin lymphoma & 6 \\
\hline Acute myeloid leukemia & 5 \\
\hline Acute lymphocytic leukemia & 4 \\
\hline Myelofibrosis & 4 \\
\hline Chronic lymphocytic leukemia & 1 \\
\hline Chronic myeloid leukemia & 1 \\
\hline Waldenstrom macroglobulinemia & 1 \\
\hline
\end{tabular}

Oncol Nurs Forum. Author manuscript; available in PMC 2016 January 01. 


\section{Table 2}

Patient-Reported Sleep and Quality of Life ( $=39)$

\begin{tabular}{|c|c|c|}
\hline Variable & $\mathbf{x}^{-}$ & SD \\
\hline Physical functioning & 63.08 & 24.75 \\
\hline Role functioning & 29.49 & 34.08 \\
\hline Emotional functioning & 67.74 & 21.3 \\
\hline Cognitive functioning & 72.22 & 22.73 \\
\hline Social functioning & 45.3 & 35.65 \\
\hline Global quality of life & 45.51 & 19.85 \\
\hline Fatigue & 74.07 & 23.41 \\
\hline Nausea or vomiting & 50 & 29.62 \\
\hline Pain & 61.11 & 34.69 \\
\hline Dyspnea $^{a}$ & 21.37 & 29.11 \\
\hline Sleep disturbance ${ }^{a}$ & 54.7 & 37.84 \\
\hline Appetite loss $a$ & 71.79 & 33.8 \\
\hline Constipation $^{a}$ & 13.68 & 28.32 \\
\hline Diarrhea $^{a}$ & 56.41 & 35.99 \\
\hline Financial impact $a$ & 39.32 & 37.36 \\
\hline
\end{tabular}

Note. Scores based on a 0-100 scale range on the European Organisation for Research and Treatment of Cancer Quality of Life QuestionnaireCore 30. Higher scores represent better quality of life and a higher level of functioning. 
Table 3

\begin{tabular}{|c|c|c|c|c|c|}
\hline \multirow{3}{*}{\multicolumn{2}{|c|}{ 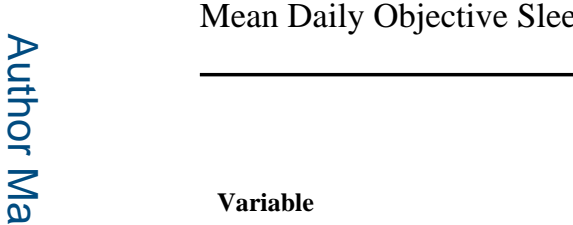 }} & p Parar & ters & $\mathrm{J}=40)$ & \\
\hline & & \multicolumn{2}{|c|}{ Nighttime Sleep } & \multicolumn{2}{|c|}{$\begin{array}{c}\text { Nighttime Sleep } \\
\text { and Daytime Naps }\end{array}$} \\
\hline & & $\mathbf{x}^{-}$ & SD & $\mathbf{x}^{-}$ & SD \\
\hline$\frac{1}{20}$ & Total sleep time (minutes) & 232.38 & 71.16 & 341.59 & 141.06 \\
\hline ב. & Sleep latency (minutes) & 15.38 & 14.89 & 24.09 & 18.07 \\
\hline & Sleep efficiency (percent) & 42.26 & 8.4 & 55.07 & 10.01 \\
\hline & Wake after sleep onset (minutes) & 313.58 & 120.46 & 220.72 & 105.32 \\
\hline & Number of awakenings & 31.73 & 12.93 & 28.64 & 13.1 \\
\hline & Naps & - & - & 7.5 & 5.84 \\
\hline
\end{tabular}

Note. One patient had no defined sleep periods during the 96-hour study period. 